\section{Investigating Environmental Performance Management}

\author{
Vipin Gupta ${ }^{1}$ \\ ${ }^{1}$ The Jack H. Brown College of Business and Public Administration, \\ California State University, San Bernardino, USA \\ Yi Zhang ${ }^{2}$ \\ ${ }^{2}$ College of Business, Zayed University, Abu Dhabi, UAE
}

Received on

02/02/2018

Approved on

05/17/2019

Responsible editor:

Prof. Dr. Leire San José

Evaluation process:

Double Blind Review

\begin{abstract}
Purpose - Even though there is a growing recognition of the externality costs of low environmental performance by firms, there continue to be significant inter-firm differentials in environmental performance management. We build on the theories of strategic management to inquire into the factors contributing to these differentials.
\end{abstract}

Design/methodology/approach - Using a 2015 survey sample of Chinese small and medium enterprises, we empirically investigate the alternative thesis that the profit maximization motive constitutes the appropriate heuristic for the performance management of corporate social responsibility factors.

Findings - The green capability of a firm is an aggregate of green trading and the investments that the firm has made in green initiatives that are complementary to its strategic business model. The profit aspiration level of firms has a negative influence on their green programing, while transformational leadership has a positive influence.

Originality/value - We develop seven propositions represented as algebraic relationships to interpret these factors.

Keywords - Environmental performance management, Green capability, Profit aspiration level, Transformational leadership, Small and medium enterprises

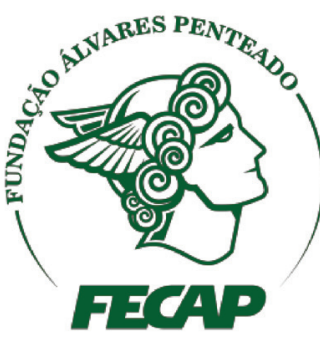

Review of Business Management 


\section{Introduction}

One of the major dilemmas for environmental performance management is the presence of externalities (Tirole, 2008). The environment as a resource is a public good, so the costs of its depletion are shared collectively, even if the conversion of environmental resources yields private benefits. Similarly, the benefits of its accretion are shared collectively, even if the costs of this accretion are private costs (Goodstein, 2011). Greater environmental consciousness at the social level, however, has helped foster awareness about this issue. Society has become conscious of holding firms accountable for environmental resource depletion and rewarding firms for accretion, such as through preferential relationships, penalties, and premiums (Hoffman \& Nembhard, 2014). Firms have also become more conscious, building transparency into their environmental accountability, recognizing their liabilities for depletion, building capabilities to lower depletion and raise accretion even at higher costs, recognizing environmental capabilities and the costs of investments in these capabilities as baseline costs of doing business, and educating their customers so that they pay these passthrough costs and sustain what we refer to as "environmental performance management."

In this study, following the fundamentals of strategic management theories (e.g. Drnevich \& Kriauciunas, 2011; Duncan \& Barrett, 2007; Eesley \& Roberts, 2010; Hart, 1995; Teece, Shuen, \& Pisano, 1997; Zott, 2003), we propose that the inter-firm variations in environmental performance management are a dynamic function of firm motivation and capabilities. Central, more powerful, and enduring firms, have greater structural, behavioral, cognitive, and emotional motivations for this environmental performance management. Being more visible and central, they have more to lose from social exclusion, and so they are more likely to evidence loss aversion (Kahneman \& Tversky, 2000; Krishnan \& Kozhikode, 2015). The question is whether they also have more capabilities. As holders of central positions, they are likely to have more resources, and possibly more organizational slack, to invest in building the capabilities for environmental performance management. However, if they did not focus on building these capabilities in the past, then they may have to rely on sourcing from outside. Given that environmental performance management capabilities are becoming critical differentiators (Hoffman \& Nembhard, 2014), it may not be possible to source such capabilities from other central firms who will be very protective of those capabilities as being at the core of their strategic business models.

Even among less central, less powerful, and younger firms, the capabilities for environmental performance management may be quite strong (Hofmann, Theyel, \& Wood, 2012). Some of these firms may be environmental specialists and missionaries, who have chosen to apply their environmental performance management capabilities to specific markets or industries. The environmental missionary Tesla, for instance, has chosen to invest in the automobile industry. Environmental performance capabilities may be quite heterogeneously distributed among less central firms. Some may have greater environmental capability than the compensation they can get from the market, and be willing to trade their extra capability. Some others may have below-median operating costs, and be a great potential collaborator for central firms to source green products and services. Of course, many non-central firms may neither have sufficient environmental capability nor belowmedian operating costs, and so may not be viable participants in the common global market.

Considering the viable participants in the common global market, then, two of the tactics available to a central firm for building capability for environmental performance management is to either trade supplementary green capability from other (central or) less central firms, or to have these other firms service its sourcing needs for competitive green resources as intermediate 
inputs. We refer to these as supplementary capability trading and competitive resource servicing tactics, respectively. A third, final tactic is for firms to make investments in building their own environmental performance capability, if such investments are complementary to their own core capabilities. The environmental performance management decisions of firms will be a dynamic function of the conditionality that shapes the benefits and costs of these different tactics.

In this study, we use the first principles method to ontologically derive the dynamic conditionality for environmental performance management for a firm. In philosophy, "first principles" is synonymous with an axiomatic or ontological method. A first principle is a basic, foundational, self-evident proposition that is not conditional on any other assumption. In mathematics, the first principles method is also known as a delta method, because it helps us evaluate changes in the value of the conditionality, as a function of changes in the value of a decision variable, at a constant value of a co-conditionality. After presenting the algebraic equations for the dynamic conditionality, we show exploratory empirical evidence for the core factors that influence environmental performance management, or what we refer to as green programing, using a 2015 survey sample of small and medium enterprises from China. Specifically, we apply the proposed axioms to demonstrate why a strong profit maximization motive may compete with the green programing objective. Environmental performance management is undermined when firms operate according to Milton Friedman's doctrine on profit maximization as the firm's sole objective (Friedman, 1962). Finally, we discuss the managerial and research implications.

\section{Literature Review}

In order to set the context for our ontological analysis, we first review extant and emerging literature and highlight pertinent conditions for dynamic environmental performance management.
Extant literature on proactive greenoriented firms is guided by three major theories. The first is a predominant theory of social legitimacy in which a proactive green orientation as concordant with the norms of social responsibility (Suchman, 1995). Stakeholder endorsement of social legitimacy empowers a firm to translate its proactive green orientation into above-normal green performance, through two paths: (1) The servicing path. Stakeholders who service the formative legitimacy of a firm are less likely to impede its green-oriented behaviors, for the sake of normative profiting. For instance, regulation stakeholders - such as investors, mentors, and guides - may provide not only resources but also political leverage to a firm, empowering it to engage in compensatory consumption as a responsible citizen. (2) The trading path. Stakeholders who trade formative legitimacy from a firm are more likely to compensate it for green-oriented behaviors, thereby mitigating the trade-offs with normative profiting. For instance, market stakeholders, such as workforce, vendors, and customers, may gain reputational benefits from having an intense spirit of technological innovation, if they socially network with proactively green-oriented firms.

The second is a dominant theory of institutional identity, where green performance is discordant with the norms of market efficiency (Grossman \& Kreuger, 1991). The institutional identity of green performance as a trading effect of preferential investments by regulation stakeholders may limit the sustainability of green performance, because of two forces: (1) Investment forces. Market stakeholders may view the transformative (supernormal) green performance of a firm as a sign of inherent invisible trade-offs with market performance, and consequently impose subtle informal pressure on the firm to ascend its market performance aspirations. For instance, they may pressure the firm to apply a non-systematic political risk multiplier in its investment decisions. (2) Capability forces. Regulation stakeholders may 
view the transformative (supernormal) profiting of firms that have a constant formative green orientation as a sign of inherent invisible tradeoffs with social responsibility, and consequently impose strong formal pressure on them to self-regulate their profiting. For instance, they may strengthen the capability standards to be identified as green-oriented, thereby increasing the institutional costs of compliance of proactive green leaders.

The third is a deciding theory of the survival of green performers as being discordant with the norms of regulatory selection fitness (Porter \& van der Linde, 1995). The survival of green performers as a servicing effect of market stakeholders may raise questions regarding the fitness of regulatory selection forces, under two conditions: (1) The exchange condition. Alternative ecosystem stakeholders may view the normative presence of green performers as an invisible sign of the target ecosystem's abundance of green factor endowments, and may therefore seek to exchange their alternative (regulatory and market) resources to trade these green endowments. They may identify local regulatory stakeholders as being strong, and local market stakeholders as being weak. Consequently, they may seek to exchange local regulatory stakeholders with global regulatory stakeholders whose values are concordant with the value of the global market stakeholders, who are the protagonists of the global exchange system guided by setting stringent green norms that are beyond the capability of the global market to fulfill using its own resources, and therefore inspire global stakeholders to seek innovative linkages with alternative cost-effective resources. (2) The growth condition. Target ecosystem stakeholders may view the normative absence of green performers as an invisible sign of an alternative ecosystem's abundance of regulatory and market factor endowments. Consequently, they may seek to exchange the services of the global regulatory and market stakeholders to manage the local exchange system. As the stakeholders exchange self-managing local firms for institutionally-managed global governance structures, the local market experiences decreasing growth, while the global market experiences increasing growth.

Together, when all three theories are at work, then the firms who rely on the servicing of local regulation stakeholders to legitimize their proactive green behaviors end up with an increased cost of servicing global stakeholders. On the other hand, the firms who sensitize global regulation stakeholders regarding the value of being proactive in their green behaviors enjoy increased benefits of management rights over the local market stakeholders who are seeking alternatives to the local regulation stakeholdermediated green performance. Thus, there is a critical gap in the literature on how the market for green performance might work without selfattracting the cost-increasing servicing of global stakeholders. Recently, three new ideological perspectives have emerged that highlight pertinent conditions for dynamic environmental performance management within local markets.

To begin with, the first new perspective, advanced by Gupta and Zhang (2019), is that the firms in a market engage in an exchange of environmental performance with society. We refer to this as the proficient market perspective. When the society puts a low value on environmental performance, the firms tend to put less emphasis on environmental performance management. Conversely, when the society puts a high value on environmental performance, then the firms will put more emphasis on environmental performance management. We refer to this as the market system-social system exchange condition. The social aspirations for environmental performance management operate as a contingency factor in firms' decisions to emphasize both environmental and technical (i.e. core or strategic) performance versus mostly technical performance.

The firms within a market engage in trading environmental performance management capabilities with other (central and/or) noncentral firms. When the non-central firms 
have greater environmental capability than what the society values and are willing and able to compensate for them, they are likely to identify this extra environmental capability as supplementary to their business model and be open to trading it such as by freely sharing it with their preferred collaborators as a way to gain social capital. Similarly, when the non-central firms have below-median operating costs at a given level environmental capability, then they will enjoy a competitive advantage for servicing sourcing needs for the green inputs of the central firms. We refer to this as the market system trading and servicing condition. Weaker organizational aspirations, but stronger social aspirations, for environmental performance management, operate as a catalyst factor in firms' decisions to engage in trading environmental capabilities or green servicing with other firms. The fact that organizational and social aspirations are different and have a different effect on firm behavior has been demonstrated in recent research (Kim, Finkelstein, \& Halbelian, 2015).

The second new perspective we use is the scientifically well-established view of firms as organizations that use the force of heuristics to guide their decision-making (Groner, Groner, \& Bischof, 1983). We refer to this as the proficient regulatory (at the national level of inter-national exchanges), governance (at the local level of inter-organizational networks), management (at the corporate level) perspective. We propose that the firms use the following followershipleadership heuristic for intuitive decision-making about environmental performance management leadership. As long as social aspirations for environmental performance exceed their environmental performance management capabilities, they continue focusing more on the management of exchange with the social system and the management of trading within the market system. However, if they are able to conceive investment in environmental performance management as complementary to their core technical capabilities, then they prioritize leading the market and possibly even the society with their proactive green orientation as well. We refer to this as the organization system investment complementary condition. Stronger investment complementarity operates as a risk mitigation factor in the firm's decisions to make proprietary and captive investments in environmental performance management capabilities. When investments in environmental performance management capabilities are complementary to a firm's core technical capabilities that form the basis of its strategic business model and its differentiated competitive advantage, then the costs of investment in such capabilities tend to be lower and the benefits greater.

The third new perspective is the empirically substantiated view of firms as using the global market to decouple investment in environmental performance management capability from growth in their core technical capabilities (Jackson, 2009). We refer to this as the proficient social ecosystem perspective. We propose that as firms prioritize leading the global market with their proactive green orientation, they attract locally active green-oriented firms seeking to be their followers. The locally active greenoriented firms are not conscious of the fact that the proactive green-oriented global firms are only seeking to discover a path to manifesting green performance management - they do not actually have green performance management capability. Consequently, they are motivated to exchange their active green orientation with additional responsibilities for growing their green performance management capability. On the other hand, global proactive green-oriented firms are able to grow their environmental performance capability through the investment of locally active green-oriented firms, and invest in increasing returns for growth in their core technical capabilities. Overall, the global social ecosystem thus enjoys disproportionate economic growth, with little, zero, or even negative environmental costs. On the other hand, the local social ecosystem enjoys disproportionate environmental 
costs, as it seeks to accrue proportionate economic benefits to manage its growing responsibility for servicing the challenging green technological mandates of the global leaders.

Together, when all three ideological perspectives are at work, then the global firms that place a greater mental priority on environmental performance management end up with increased value from trading within the global market. In the global market, nations enjoy increased ecological as well as economic value addition, contributing to positive psychological as well as social well-being. On the other hand, in local societies, nations see increased ecological as well as economic costs of social responsibility - i.e. responsibility for servicing the extrinsic social ecosystem, with increased psychological stress as well as social pressures. The firms within local societies experience a loss of face for not keeping up with their cultural reputation for being green performance oriented (mental harmony with nature). The firms within the global market experience a boost in their self-concept based on the mental mastery of nature through a focus on their core technical capabilities. We refer to this as the proficient (mental) programing perspective.

\section{I Ontological Derivation of the Dynamic Conditionality for Environmental Performance Management}

Next, we ontologically derive the decision conditionality of environmental performance management, or what we refer to as green programing, through a set of dynamic mathematical equations. These equations are from the unpublished Ph.D. dissertation work of Gupta (1998). Based on the literature review, we identified five steps of dynamic conditionality.

First is the predominant cost effect of social legitimacy theory. The environmental cost that firms are willing to bear and take accountability for is a proportionate function of the extent to which society values environmental performance and identifies with being green, and the organizational strategic business model has linkages with these values. We refer to these activated green social culture linkages of a firm as its green social culture effect.

\section{Green cost $\alpha$ Green social culture effect (1)}

Second is the dominant trading effect of institutional identity theory. Green trading opportunities are more likely to be discovered and recognized when organizations have a strong green identity and values and the firm's strategic business model has linkages with these organizational values and identity. We refer to these green organizational culture linkages of a firm as its green organizational culture effect. Organizations with activated green identities are likely to be transparent about their green initiatives, and also be proportionately alert about the green initiatives of other firms.

Green trading $\alpha$ Green organizational culture effec (2)

Third is the deciding servicing effect of organizational fitness theory. Green servicing opportunities are more likely to be discovered and recognized by a firm when not only the organizations have strong green identifies, but the society also values green performance. The latter condition should allow firms to leverage the market for sourcing as well as to meet their aspirations for green organizational identity.

Green servicing = Green organizational culture effect $x$ Green social culture effect (3)

Fourth is the metaphysical exchange effect of the proficient market perspective. Firms will respond to the market system-social system exchange condition through green trading and green servicing within the market system. They will strive to ensure that green trading and green servicing together are able to match their aspirations for green exchange.

Green exchange $=$ Green trading $x$ Green servicing (4) 
Fifth is the dynamic investment effect of the proficient management perspective. Firms will seek to make proprietary investments in environmental performance management capability if they are able to service market sourcing needs through their green investments and if these investments have strong complementary linkages with their strategic business model. We refer to these complementary linkages as the green corporate effect.

Green investment $=$ Green Servicing $x$ Green corporate effect (5)

Sixth is the technological capability effect of the proficient social ecosystem perspective. Firms will respond to the market system trading and servicing condition by appraising their own environmental capabilities. If their environmental capabilities are complementary to their core technical capabilities (i.e., their strategic business model), they are likely to be able to create value through servicing the sourcing needs of the market. Otherwise, they are likely to seek to capture value through trading supplementary green know-how with their preferred partners, as a way to gain social capital.

Green capability = Green corporate effect $x$ Green trading (6)

Finally, there is the consequential effect of the proficient (mental) programing perspective. A firm's environmental performance management will vary as a function of its proprietary and complementary investment in environmental performance management capability (i.e. its green investment) and its capacity to indirectly capture the value of its supplementary green know-how through social trading.

Green programming $=$ Green investment $x$ Green trading (7)

Based on 3, 5, and 7,
Green programming = Green organizational culture effect $x$ Green social culture effect $x$ Green corporate effect $x$ Green trading (7')

Based on 2 and 7',

Green programming $\alpha$ Green organizational culture effect $x$ Green social culture effect $x$ Green corporate effect ( 7 ")

Put differently, firms are more likely to engage in environment management practices when they have strong ecological consciousness, when their social linkages have strong ecological consciousness, and when they have knowledge about how green initiatives can be aligned to complement their strategic performance management model.

\subsection{An empirical investigation into Friedman's profit maximization doctrine}

The dynamic principles of green programing mean that firms take green costs into account when society values being green. Now, this leads to the classic dilemma of firm behavior, which is often referred to as Friedman's doctrine (Friedman, 1962). Shouldn't firms that use the simpler heuristics of merely prioritizing profit maximization (i.e. growth) be automatically able to achieve superior levels of green programing? Why should firms strive to be conscientious about their social responsibilities, such as environmental performance? Therefore, we hypothesize that:

H1 (Alternative to social cost-escalating legitimacy theory): Firms'profitmaximization motives are positively associated with their green programing.

If Friedman's doctrine is valid in explaining the behavior of firms, then a firm's green programing should be fully explained by its profit maximization motive. However, if the ontological principles we have derived are valid, then we should find significant power in the green 
corporate effect, green organizational culture effect, and green social culture effect.

Profit aspiration level as a sign of the Green corporate effect: We propose that higher profit aspiration levels may be interpreted as a sign of supplementary green capability (i.e. organizational slack). Strong profit aspirations indicate to firms that they have greater capability than what they have activated. As we noted earlier, supplementary green capability implies that the firms are not able to capture value strategically from their entire green capability through market-based servicing. Instead, they look for more tactical opportunities, in the form of free trading of their uncompensated green know-how with strategic collaborators in an effort to build social capital. To the extent that social capital gains are only indirectly related with growth, and in the future that is uncertain, firms are likely to perceive such trading in less attractive terms. Therefore, we hypothesize that:

$\mathbf{H 2}$ (The social cost of institutional identity theory): Firms' profit aspiration levels are negatively associated with their green programing.

We now investigate if profit aspiration levels make heuristics based solely on the profit maximization motive inadequate. We propose that the profit maximization motive does moderate (i.e. behaviorally and inappropriately bias) the relationship between profit aspiration level and green programing. When the profit maximization motive is strong, then firms may be more inclined to lower their priorities on green programing as their profit aspiration level increases - since, based on their aspirational signals, they are likely to believe that a lower level of green programing is needed to achieve their high profit aspirations. Firms are likely to perceive less need to reduce green programing with increasing profit aspirations when their profit maximization motive is weak. Thus, the positive effect of the profit maximization motive on green programing will decrease as the firm's profit aspiration level rises. Therefore, we hypothesize that:
H3 (The social cost of managing organizational fitness theory): The negative relationship between firms' profit aspiration levels and their green programing is stronger when the firm's profit maximization motive is strong than when this motive is weak.

Transformational leadership as a Green organizational culture effect. We consider transformational leadership as a dominating force in activating green organizational identity. Transformational leadership tends to promote an integrative and futuristic perspective (House et al, 2004). It helps firms visualize how socially desirable performance dimensions actually make business sense as well (Angus-Leppan, Metcalf, \& Benn, 2010; Waldman et al., 2006). It should therefore help firms transform their operating models, in ways that help them endogenize social benefits and social costs and encourage a complementary perspective of firm capabilities. When firms are able to more effectively integrate their environmental know-how into their core operating model, then they are more likely to perceive environmental performance management in positive terms. Therefore, we hypothesize that:

H4 (The social benefit of the proficient
market perspective): Firms' transformational
leadership is positively associated with their
green programing.

We investigate if transformational leadership also makes heuristics based solely on the profit maximization motive inadequate. We propose that the profit maximization motive does moderate (i.e. behaviorally and inappropriately bias) the relationship between transformational leadership and green programing. Transformational leadership may not be as effective in sustaining green programing, if the profit maximization motive is strong. Transformational leaders take a rather broader and futuristic view, pursuing a multiphase strategy to reposition today's businesses while finding new ways to grow (Anthony \& Schwartz, 2017). Therefore, viewing 
environmental performance management through a strategic lens of alignment with the core business model may be very transactional and constraining to transformational leaders. They are likely to focus more on trading their environmental know-how through social relationships, as a way to strengthen social consciousness and the capacity for green performance management. A strong profit maximization motive may inhibit this social approach. Conversely, if the profit maximization motive is weak, then the need for strategic alignment of green programing with the firm's core operating model will be low. Then, transformational leaders may find more space for both complementary as well as supplementary initiatives for advancing their green programing. Therefore, we hypothesize that:

H5 (The social benefit of the proficient management perspective): The positive relationship between firms transformational leadership and their green programing is stronger when a firm's profit maximization motive is weak than when it is strong.

Formative product-market context as a Green social culture effect. If profit aspiration levels as well as transformational leadership become inadequate when the profit maximization motive is strong, then how can a firm mitigate these inadequacies? We investigate this issue in terms of the role of the context. In other words, are firms in some contexts more likely to experience the profit maximization model as competing with the green programing objective, than those in other contexts? We propose that formative productmarket contexts reflect the contemporary green social culture effect. Since societies have become increasingly environmentally conscious, firms predominantly engaged in formative productmarket contexts are likely to be more connected with the green social culture effect. Additionally, if the product-market context is formative in nature, then firms may have greater degrees of freedom in taking accountability for the environmental costs. In formative phases, competitive rules of the game are still being formed, and firms are in a better position to inform and shape these rules, and to establish being green as part of the dominant operating model for success (Utterback \& Abernathy, 1975). On the contrary, in normative phases, firms tend to operate in more competitive spaces, where different constituents are more invested in defending their value shares. The firms and their constituents are likely to show loss aversion, and avoid any moves that might potentially reduce their growth. The firms in dominant positions tend to be insecure about their positions, and are more willing to embrace negative behaviors (Krishnan \& Kozhikode, 2015). Therefore, we hypothesize that:

H6 (The social benefit of the proficient social ecosystem perspective): Firms' productmarket context normativity is negatively associated with their green programing.

Consequential green programing as a social benefit cost ratio of the proficient programing perspective. Transformative leadership motivates the global workforce to seek cost-effective follower social networks using local search heuristics. Profit aspiration levels manipulate follower social networks to diffuse the value of their green performance to help the socially-minded entrepreneurial workforce to fulfil its aspirational objectives. Responsible management of the ascending global demands for green development with local worker social costs contributes to increasing global worker social benefits. However, there may be a limit to the capability potential and/or kinetic investment power of local firms. Under the conditions of escalating costs of environmental performance, local governments may set supernormal environmental management aspirational goals, as a path to motivate global firms to countertrade their entire green programing traded from diverse local social networks around the world with local firms. Large firms with a supernormal market, regulation, and social ecosystem resources may 
seek to fulfill the mandates of local government through investment into researching alternatives to global green programing practices, as a path for developing that into corporate green capability. On the other hand, small and medium enterprises, with limited market, regulation, and social ecosystem resources, may seek to sustain their survival by trading and capturing the investment value of global green programing practices, using the global, unique, inclusive, diverse, engaging, and responsible (GUIDER) management of the global leaders. Through self-organizing national networks, large firms may discover the global cost-effective value of the green programing practices of local small and medium enterprises. They may perceive the value of their discovery to be a consequence of their own conscious determination, as evidenced by the investment in discovery-oriented research and the capability for developing social networks. Local governments, on the other hand, may perceive increasing green programing as well as increasing economic cost-saving benefits as the consequence of their managerial willpower to advance next-generation green programing standards. Global institutions may consider this as unfair competition, and pull out from the transnational aspirational goals of increasing environmental performance as well as creating expectations for their large firms to weaken their linkages within local nations. Under these conditions, local small and medium enterprises need to identify alternative, diverse global channels for sustaining the positive worker social benefit cost ratio of green programing, or else they may not be able to responsibly manage their green programing. Therefore, there is a need to empirically substantiate the power of the small and medium enterprises in a local emerging market to responsibly manage their green programing.

\section{Method}

Sample and data. The east coast of China is considered to be "the land of SME seeds and buds." Along this coast, in early 2015, we surveyed SME (small and medium enterprise) firms by enlisting the support of trainers and administrative officers of local Chinese SME administrative organizations. In China, firms are considered SMEs if they have fewer than 2000 employees and an annual turnover of less than 300 million RMB (Li \& Rowley, 2008).

We translated the original scale items into Chinese and then translated them back into English three times using three different bilingual Chinese experts. We piloted both English and Chinese language surveys on 80 senior managers, and used the responses to make further modifications in the Chinese language survey. We followed up on the distributed surveys three days later with phone calls. The respondents were given three weeks to return the completed surveys in confidential, sealed envelopes. At the end of the three weeks, 386 completed surveys were received, giving a response rate of $63.4 \%$.

$96.6 \%$ of the firms had an annual turnover of 300 million RMB or less. $90 \%$ of the firms had 500 or fewer employees; 99\% had 2,000 or fewer employees. The median age of the firms was 7 years. While $51 \%$ were single product firms, nearly $6 \%$ offered ten or more products. $80 \%$ of the firms were selling in the domestic market only; but more than $12 \%$ generated a fifth or more of their sales from overseas. The respondents had a median age of $40 ; 79 \%$ were males. About three quarters had a bachelor's degree or higher. About three quarters were c-level executives or owners, and another fifth were mid-level managers.

\section{Dependent variable}

Green programing $(\alpha=0.87)$ : we used Judge and Douglas's (1998) measure, where respondents rated a firm's overall environmental performance management relative to others in their industry on four seven-point scale items. One sample item, for example, was: "Over the last 12 months, compared to other firms, how well has your firm prevented and mitigated environmental crises?" This variable measures the perceived worker social cost-benefit ratio of the green programing that a firm has. 


\section{Independent variables}

Strength of profit maximization motive: Since asymptotically the profit maximization motive is aligned with the growth maximization priorities of a firm (Latouche, 2013), we asked the respondents to rate the importance of growth in three dimensions over the past 12 months - sales, profit, and market share. We computed the factor score composite of these three dimensions (accounting for $63.33 \%$ of the variance; $\alpha=0.71)$. We then scored the strength of the profit maximization motive using visual examination and natural breaks in the spread of the firms along the approximate quartile cut-offs: $<-.5=1 ;-.5$ to $0=2 ; 0$ to $.8=3 ;>.8=4$. Social importance of growth is a measure of extrinsic value aspiration, i.e. a firm's motive. Firms that place disproportionate social value on profits may invest these profits in growth of sales or market share, or seek to retain these profits as returns to investors in the form of dividends or capital appreciation.

Profit aspiration level: We measured this as a factor score composite of two indices: growth and productivity $(\mathrm{r}=0.41 ; \mathrm{p}<0.01)$. The growth index $(\alpha=0.75)$ is the average of the standardized values of reported growth over the past 12 months in (a) employees, (b) sales, and (c) profits. The productivity index is the logarithmic value of revenue/employees. Following Kim, Finkelstein, and Haleblian (2015), we consider productivity growth to be a crucial performance outcome that managers pay attention to and take into consideration when forming their profit aspirations. Growth is a measure of intrinsic value aspiration, i.e. the workforce's profiting psychology. Firms whose workforces psychologically value profiting may express their profit aspirations by investing in additional workforce, or in growing sales as a path for growing workforce, or in generating profit as rewards to the principal leaders that are catalyzing growth.
Product-market context normativity: We used Lumpkin and Dess's (2001) measure. The participants reported a percentage of firm revenues accounted for by products/services at four lifecycle stages: introduction (I), growth (G), maturity (M), and decline (D). Product-market context normativity is a weighted average that uses the following formula: $1^{*} \mathrm{I}+2^{*} \mathrm{G}+3^{*} \mathrm{M}+$ $4^{*} \mathrm{D}$. This is a single continuous stage of product lifecycle measure, where a higher score reflects the firm's average involvement in a later (mature) stage of the product lifecycle. The sample average is 2.34 , indicating a group of firms whose product portfolio is between the growth cycle and the maturity cycle, i.e. is beginning to experience product-market context normativity. A postgrowth context implies that the growth of the firms is cooling down, because of escalating cost trade-offs and challenges in sustaining aspirational profit-making due to social ecosystem, regulatory, and/or market factors.

Transformational leadership: We measured this as the mean of two measures. The first measure is Waldman, Ramirez, House, and Puranam's (2001) charismatic leadership scale ( $\alpha=0.89$ ), where respondents rate their leaders on seven seven-point items $(1=$ much worse, $7=$ much better). One sample item, for example, was: "Compared to other leaders, how well can your leaders provide a vision of what lies ahead?" The second measure is Montoya-Weiss, Massey, and Song's (2001) political skill scale ( $\alpha=0.86)$, where respondents rate their level of agreement with six seven-point scale items regarding their ability to connect with people. One sample item was: "I usually try to find common ground with others." A politically savvy followership that believes in the social charisma of its leadership constitutes a dynamic unit of market exchange - in the sense of being highly motivated to exchange cost-effective programs by transcending the local searchoriented transactional followership mindset, instead developing appropriate global market linkages as holistic units of transformational leadership. 
Demographic variables: We controlled for two demographic variables: firm age and firm size (numbers of employees). SMEs' age and size may shape environmental performance management.
The descriptive statistics and the correlations among the dependent and independent variables are shown in Table 1.

Table 1

Correlations among the dependent and independent variables

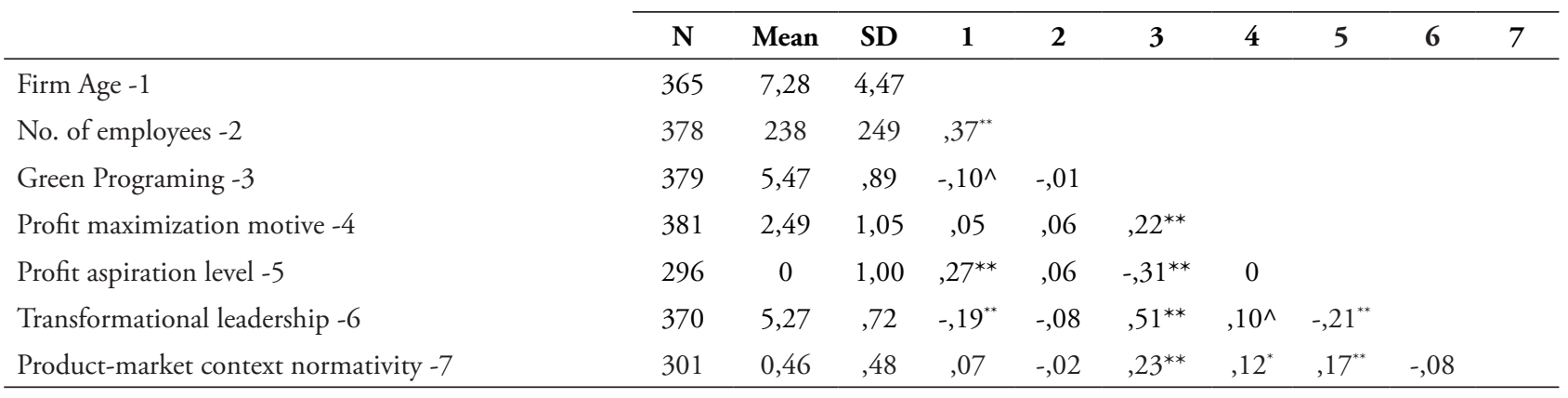

Notes. $\wedge,<.10,{ }^{*}, \mathrm{p}<.05 ;{ }^{* *}, \mathrm{p}<.01$

Validation check. When using the survey method, the systematic survey method effect could substantially inflate or deflate the relationship between the independent and dependent variables, and thus threaten the validity of the findings. One of the recommended techniques to minimize the threat of the common method effect is "methodological separation" - i.e. using different formats to measure various variables (Craighead, Ketchen, Dunn, \& Hult, 2011). Both our survey and the transformations were guided by the use of different formats to measure our independent variables. To further statistically validate for the common method variance, we used Harman's single-factor test. We first subjected all variables to exploratory factor analysis, to check if the first factor accounted for a majority of the variance in the variables (Harman, 1976). We further compared the one-factor model with the multi-factor model using the chi-square difference test in confirmatory factor analysis (Craighead, Ketchen, Dunn, \& Hult, 2011). Both types of analysis did not provide any evidence of common method variance.

\section{I Findings}

We used multiple regression analysis to test our hypotheses. The results are shown in Table 2. Model 1 is the null model using only the demographic variables. Neither of the demographic variables is significant. 
Table 2

Multiple Regression Analysis - Standardized beta coefficients

\begin{tabular}{|c|c|c|c|}
\hline & \\
\hline & 1 & 2 & 3 \\
\hline \multicolumn{4}{|l|}{ Step 1} \\
\hline Age of the firm & $\begin{array}{c}-, 10^{\wedge} \\
(-1,71) \\
\end{array}$ & $\begin{array}{c}, 04 \\
(, 73) \\
\end{array}$ & $\begin{array}{c}, 04 \\
(, 72)\end{array}$ \\
\hline No. of employees & $\begin{array}{c}, 01 \\
(, 14) \\
\end{array}$ & $\begin{array}{c}, 04 \\
(, 73) \\
\end{array}$ & $\begin{array}{l}, 03 \\
(, 46) \\
\end{array}$ \\
\hline \multicolumn{4}{|l|}{ Step 2} \\
\hline Profit maximization motive & & $\begin{array}{c}, 15 \\
(2,94) \\
\end{array}$ & $\begin{array}{c}, 97^{*} \\
(2,51) \\
\end{array}$ \\
\hline Profit aspiration level & & $\begin{array}{l}-, 22^{* *} \\
(-4,25)\end{array}$ & $\begin{array}{c}-, 04^{* *} \\
(-, 37) \\
\end{array}$ \\
\hline $\begin{array}{l}\text { Transformational } \\
\text { leadership }\end{array}$ & & $\begin{array}{l}, 50^{* *} \\
(9,74)\end{array}$ & $\begin{array}{l}, 66^{* *} \\
(7,60) \\
\end{array}$ \\
\hline $\begin{array}{l}\text { Product-market context } \\
\text { normativity }\end{array}$ & & $\begin{array}{l}-, 16^{* *} \\
(-3,15) \\
\end{array}$ & $\begin{array}{c}-, 17 \\
(-3,33) \\
\end{array}$ \\
\hline \multicolumn{4}{|l|}{ Step 3} \\
\hline $\begin{array}{l}\text { Profit aspiration level } \mathrm{x} \\
\text { Profit maximization motive }\end{array}$ & & & $\begin{array}{c}-, 20^{\wedge} \\
(-2,20)\end{array}$ \\
\hline $\begin{array}{l}\text { Transformational } \\
\text { leadership x Profit } \\
\text { maximization motive }\end{array}$ & & & $\begin{array}{c}-, 85^{*} \\
(-2,14)\end{array}$ \\
\hline $\mathrm{R}^{2}$ &, 01 &, 40 &, 42 \\
\hline Adj. $R^{2}$ &, 00 &, 38 & \\
\hline $\mathrm{F}$ & 1,63 & $27,10^{* *}$ & $21,77^{* *}$ \\
\hline $\mathrm{N}$ & 354 & 252 & 252 \\
\hline
\end{tabular}

Note. ${ }^{* *}: \mathrm{p}<.01{ }^{*}: \mathrm{p}<.05:^{\wedge}: \mathrm{p}<.10$
Model 2 includes all the independent variables accounting for $40 \%$ of the incremental variation in green programing. We found support for all our hypotheses (see Table 2). As predicted, the profit maximization motive has a statistically significant positive effect on a firm's green programing. While profit aspiration level has a negative effect, transformative leadership has statistically significant positive effects. Productmarket context normativity also has a significant negative impact. Model 3 adds the moderating effects, accounting for an additional $2 \%$ of the incremental variation. As predicted, the profit maximization motive negatively moderates the relationship between profit aspiration level and green programing, and between transformational leadership and green programing. In our sample, though, once the moderator is included, the main effect of profit aspiration level becomes nonsignificant. Figures 1 and 2 show how the profit maximization motive moderates (i.e. behaviorally biases) the two relationships. 


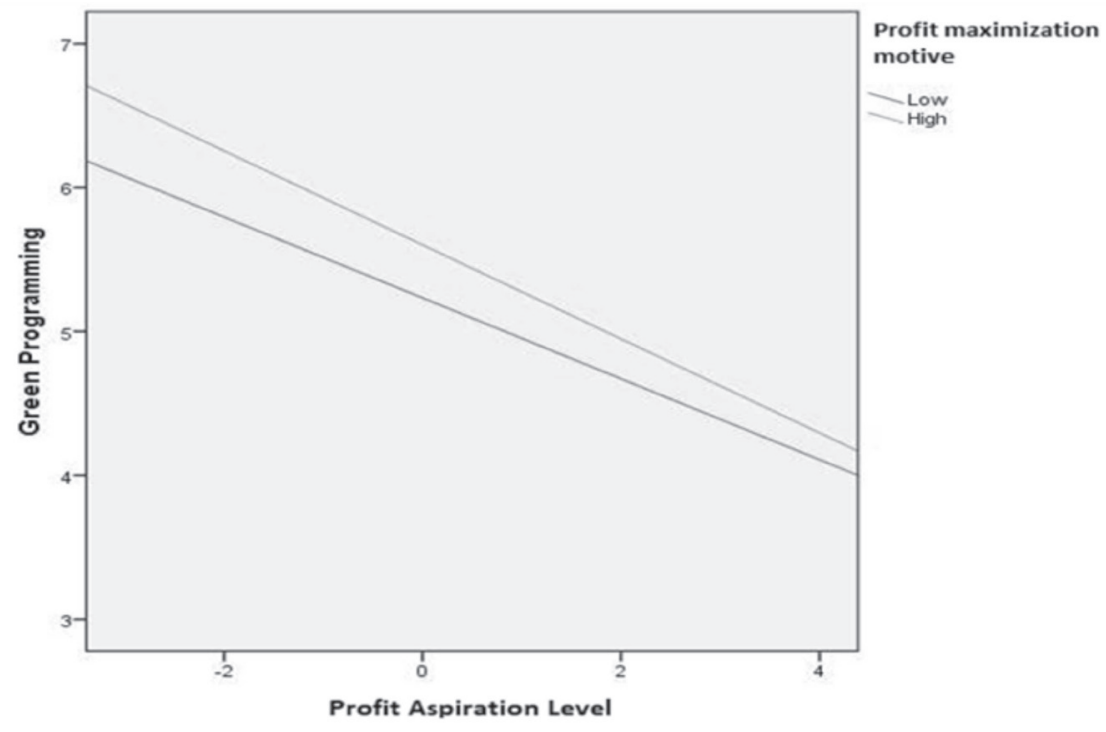

Figure 1. How profit maximization motive moderates the relationship between profit aspiration level and green Programing

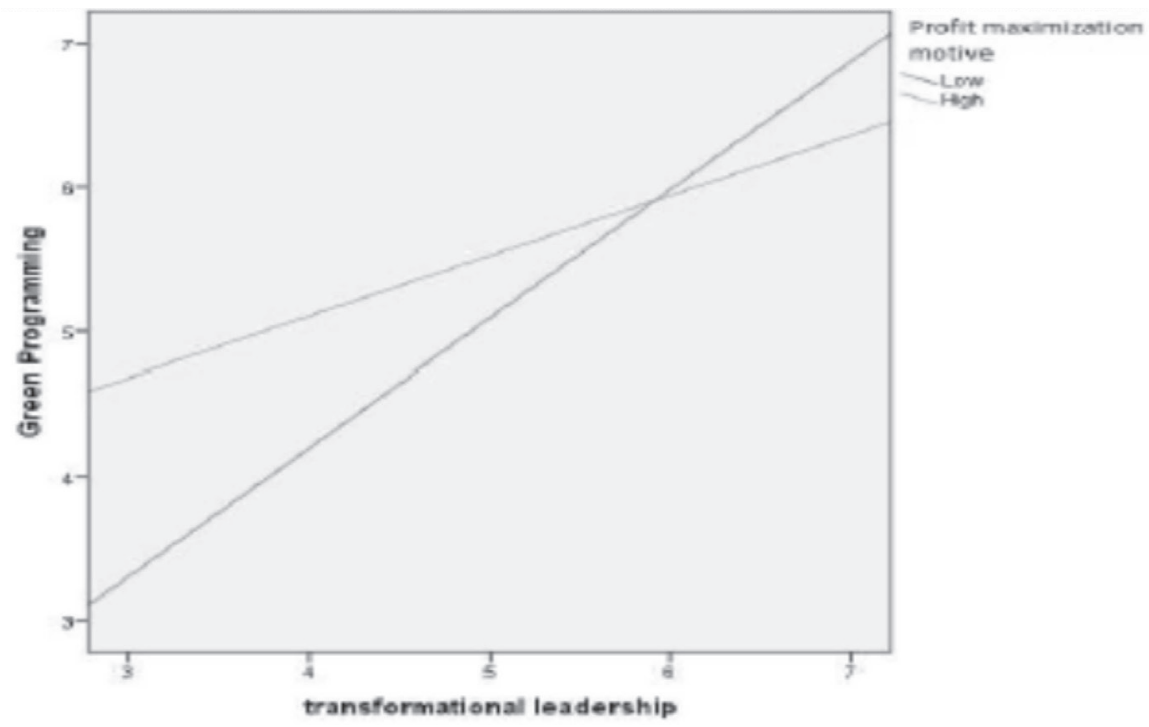

Figure 2. How profit maximization motive (growth priority) moderates the relationship between transformational leadership and green programing.

\section{Assumptions \& Limitations}

We proposed that the firms would be willing to take greater accountability for environmental costs, if the society values environmental responsibility and is willing to reward and/or punish them for their accountability or lack thereof. In practice, even if the society has green consciousness, the systems for reward and punishment may not be fully developed. Information asymmetries may impede establishing clear accountability (Gupta \& Zhang, 2019; Hoffman \& Nembhard, 2014). Firms may also manipulate information, such as by investing in impression management, which may either help them sustain higher levels of green initiatives, or 
allow them to maintain minimalist level of such initiatives (Talbot \& Boiral, 2017). Members of society may not be homogenous in their attitudes towards environmental consciousness, or in their willingness or capacity to pay for green programing. Some members may be more and others less green conscious and demonstrate greater willingness to support and compensate for green initiatives, such as employees, partners, investors, or customers (Hardcopf, Shah, \& Mukherjee, 2017).

We further proposed that firms would be willing to invest more in green programing if their strategic business model for customer servicing is based on a green platform and if they know how to align green initiatives as a complement to their strategic business model. In practice, firms may already have a legacy strategic platform, and seek tactical operational approaches to reduce their environmental footprint (Gupta \& Zhang, 2019). There may be adjustment gaps in the tactical integration of green approaches within the organization, and its translation into value proposition for the serviced customers. There may also be the temporality factor of leads and lags between when the firm investing in green programing and when it targets customer groups who are environmentally conscious and have the capacity to appropriately value green initiatives. Further, firms may not always develop green and strategic programing together. Some of the green programing may evolve independently of the strategic programing, and these two types of programing may come together at a future time as the firms discover cost-effective greener alternatives. Consequently, a firm's actual investments in green programing may not align fully with its green servicing and the complementarity of its green initiatives.

We also noted that firms would be willing to trade their supplementary green know-how that they do not know how to exploit as part of their strategic business model and customer servicing. In practice, firms may face ambiguity about the dimensions of green know-how that their customers are willing to compensate them for, and uncertainty about the value of their unexploited green know-how in the future. Therefore, firms may show a tendency to hoard some of their supplementary green know-how, and to share i.e. freely trade - some of their complementary green know-how.

We further noted that firms' trading of green know-how would be directly proportionate to their green organizational culture effect. In practice, even if firms are environmentally conscious, they may not be able to trade greater green know-how with other firms if they are in a low-trust institutional context (Mabey $\&$ Zhao, 2017). When there is low trust, firms are less willing to freely trade their supplemental know-how for social capital reasons. Sharing supplemental know-how with others may not yield any social capital benefits, if the firms cannot be trusted to reciprocate favors. On the contrary, such sharing may potentially strengthen competitors, and have adverse competitive effects for the sharing firm. Thus, green organizational identity may not be positively associated with the trading of green know-how.

We observed that the green capability of firms will be deployed in two forms: first, embodied in the products and services that the firm markets and gets compensated for (firm green complementarity or corporate effect); second, disembodied, in that the firm will trade freely with its strategic partners, as part of its social capital development effort (green trading). [Of course, firms may be able to design some hybrid solutions as well]. In practice, firms may not fully deploy their green capability. Some of their green capability may be tacit and reside as organizational slack in their human capital and/or internal networks buffered from external interactions with their business partners (Lecuona \& Reitzig, 2014). Furthermore, some of a firm's green capability may be latent, residing outside its boundaries, and lie with its social partners, who may be willing to share their experiential knowhow with it as they may not be in a position to 
fully capture the commercial value of that knowhow on their own.

We also noted that the green exchange of firms includes two dimensions. The first, servicing dimension is where firms offer green products and services to their customers in exchange for direct compensation. The second, trading dimension is where firms share green know-how with their constituents, particularly strategic partners, in exchange for potential future benefits. In practice, firms may not have full control over their green exchange. Some of the exchange might take place through informal mechanisms, such as employee turnover, and not offer the possibility for the firm to capture the value from this exchange either directly or indirectly. Nevertheless, such informal exchanges (spillover or diffusion leakages) may strengthen the local network capacity for strategic green initiatives, and offer a tertiary channel for developing new pathways for green revenues (Roper, Love, \& Bonner, 2017).

\section{I Discussion}

Building on the fundamentals of the strategic theory of the firm, we advanced the understanding of the management problem facing leading firms, as they seek to respond to the increased societal sensitivity and demands for environmental programing. Since (most) leading firms have not historically invested in or developed green programing (routines), they likely need to develop green programing. Firms have two options for developing green programing - internal investments and external trading. We observed that many non-leading firms are likely to have superior green capability, and many leading incumbent firms are likely to be a follower in green programing because of their founding and legacy effects. The leading firms may trade green know-how from these firms through outright acquisitions or other forms of trading, such as purchasing green intermediate inputs or absorbing and internalizing their green knowledge through various pathways for organizational learning. We noted that the green trading of firms is likely to be a function of their green organizational culture effect - the more conscious and aware they are of the need for environmental accountability, the more motivated they will be to search for and mobilize green know-how from the market. We noted that a firm's green capability is an aggregate of this green trading and the investments that the firm has made in green initiatives that are complementary to its strategic business model (i.e. its green corporate effect). If the firm invests in green initiatives that are not complementary to its strategic business model, then such investments are unlikely to generate sustainable green organizational learning for it. If the green investments are peripheral to the firm's business strategy, then such investments are likely to be ad hoc, opportunistic, and difficult to sustain. Accordingly, we investigated Friedman's doctrine that a firm's profit maximization motive should be an appropriate guide for its green programing.

In our empirical model tested for a 2015 sample of small and medium enterprises in China, we demonstrated that the profit maximization motive is positively associated with green programing, but there are two factors that make this motive an inadequate guide to the appropriate level of green programing. First, as the profit aspiration level rises (a proxy for the exhaustion of complementarity opportunities) it becomes increasingly more challenging for firms to sustain their green programing - especially if they have an aggressive profit maximization motive. Second, as firms embrace transformational leadership (a proxy for the green organizational culture effect), it becomes more challenging to sustain green programing if they have an aggressive profit maximization motive. We noted that firms may be able to mitigate these inadequacies (arising from inappropriate behavioral biases) through stronger linkages with the emergent social green culture. Our findings confirmed that the ties with formative product-market opportunities (a proxy for the green social culture effect) are positively associated with green programing.

In formative product-market contexts, firms enjoy more fodder for learning and experimentation. Social imprinting research suggests that the new generation of product 
markets is more likely to be in tune with the newer social values and expectations (Martínez-Cañas, Ruiz-Palomino, Linuesa-Langreo, \& BlázquezResino, 2016). Our findings suggest that firms that operate proportionately more in formative product-market contexts tend to have greater green programing.

We also find that the profit aspiration level of firms is negatively associated with their green programing. If the firms have been growing rapidly, then they may assume that green programing is not essential to their growth and has at best supplemental benefits. As the status theory suggests, such firms may also develop a sense of insecurity about their growth, and seek to rely on riskier non-responsible pathways for sustaining it (Krishnan \& Kozhikode, 2015). Thus, their motivation to sustain green programing is reduced, and the motivation to pursue alternatives to green programing is enhanced. However, when the firms have a weaker profit maximization motive, then they are less influenced by these adverse motivations.

We also find that transformational leadership is positively associated with green programing. As firms embrace transformational leadership, they become more conscious of that environment as a strategic imperative, and are more likely to seek green programing - even if it does not appear to have immediate commercial (servicing) benefits. However, when firms have a strong profit maximization motive, then transformational leadership may act to inspire members to focus only on those (limited environmental) initiatives that have a clear business case in terms of immediate commercial benefits, in order to realize profit expectations. Our findings suggest that the profit maximization motive negatively moderates (i.e. behaviorally biases) the effects of transformational leadership on green programing.

\subsection{Managerial implications}

The main implication for managers is to recognize three ways to benefit from the green know-how of other firms, particularly smaller firms that often lack resources to fully leverage their proprietary and unique green know-how. First, they may trade green services with outside vendors on competitive terms (green trading). Second, they may develop a reputation for reciprocity and being a trustworthy partner, so that outside vendors are motivated to freely trade their supplemental green know-how with them (green countertrading). Third, they may develop a local presence and place-based interactions with other firms that are willing to share their green know-how for supra-strategic reasons. Therefore, we refer to this third way as green local endowment.

An additional implication is for managers to recognize three ways to profit from green exchange. First, they may trade green knowledge to accrue strategic benefits from relationships with their other partners (green diffusion). Second, they may use this knowledge for immediate competitive advantage (green servicing). Third, they may seek to not take accountability for all their environmental costs. The ability and willingness of firms to avoid full accountability is a proportionate function of their linkages with national institutional voids. For instance, firms that have linkages with astute accountants and attorneys may be able to avoid their accountability by instead investing in accounting and legal linkages. When there are national institutional voids, the nation as a whole evidently compensates for the green costs not internalized by firms, such as in the form of green subsidies or healthcare, low quality of life, and other types of costs of a negative environment, incurred either in the present or in the future. Therefore, we refer to this third way as the green national effect.

Finally, with the ongoing reduction in the barriers to free trade across national borders, firms should be able to achieve higher levels of green development than what might be expected only from their green planning efforts. However, even though globalization factors, such as improved cross-cultural exchange, communication, digital 
technologies, transportation, and socio-economic integration, has helped dramatically reduce international barriers to knowledge trading, organizations are at varying stages of capability development to engage fully in this global exchange. For a firm, the world is not entirely flat - it is still barely globalized - with, on average, $80 \%$ of trade still done within domestic borders (Ghemawat, 2007). We refer to the firm-level globalization of green knowledge trading as the green international effect.

\subsection{Academic implications}

Our study has major implications for three emerging academic streams within the inter-disciplinary environmental performance management literature.

The first is the research on managing industrial ecology using the natural systeminspired performance perspective. Scholars observe discordance between the cost-escalating waste-oriented industrial ecology and the valueaccruing exchange-oriented natural systems, and have highlighted the need to develop a natural system-inspired performance perspective (see, e.g., Socolow, Andrews, Berkhout, \& Thomas, 1994). Industrial manufacturing technology generates supernatural waste of manpower energy (many processes are routine and can cost-effectively be automated, but are not due to socially inefficient material distribution), as well as material power (many products are made from materials that outlive their consumer value and need to be recycled using cost-escalating processes, many with significant additional costs to mitigate and prevent their negative environmental effects). Natural systems, on the other hand, generate supernatural process value (which is the primary subject of scientific research seeking to create social value) as well as product value (in the form of desirable fire, water, air, and earth factors), without wasting any manpower energy (rehumanization pathway) or material power (dematerialization pathway). Rehumanization is a method of servicing a human touch for a positive ecological impact. Dematerialization is about automating the rehumanized method by trading a cost-effective system (machine) for a positive economic impact. Our findings suggest that by prioritizing trading green programing work culture practices from proficient workforces of small and medium enterprises in emerging global geographies such as China, even large firms in mature global markets such as the USA can potentially develop formative capability for creating supernormal method (process) and machine (product) value, without investing any of their manpower energy or material power. We refer to this as the neosocialization pathway. Neosocialization is about creating targeted bipolar social linkages, by exchanging energy to be diffused in a proliferating unipolar culture effect (the alternative paleo-socialization pathway). The unipolar culture effect comprises the infinity of multipolar innovative linkages that eventually compress freedom energy and consequently generate vicissitudes of amplifying frequency in both macro (national level) as well as micro (psychological) well-being.

Second, there is the research on managing environmental costs using the institutional regulatory programing perspective. Scholars observe concordance between the social costescalating regulatory programing of environmental cost mitigation standards at the local, national, and/or international levels, and the social benefit multiplier of such programing (see, e.g., Ferris, Garbaccio, Marten, \& Wolverton, 2017). The U.S. government data show that the national investment in institutionally programed environmental performance rose from $1.6 \%$ of GDP in 1990 (about $\$ 100$ billion) to $2.7 \%$ of GDP in 2000, and then fell to $0.2 \%$ of GDP in 2005 (about $\$ 27$ billion), as the rising green cultural consciousness encouraged compensatory cultural planning to activate green profit-making opportunities (United States Census Bureau, 2008). The predominant factor in the increasing cultural planning benefits is the increasing social consciousness about the rising human costs of 
ecological costs - in terms of both rising morality rates (premature death of not only children and the elderly, but also working age adults) as well as rising morbidity rates (sickness, translating into rising costs of personal sick days and family medical leave). The dominant factor in the decreasing institutional programing costs is the increasing human motivation to economically value the quality of life benefits of preventing or mitigating ecological costs. These include increasing compensatory consumption of healthy ecology recreation decisions (Phaneuf \& Smith, 2005), as well as increasing preventive investment in environment-protecting technologies such as at home and in transportation (Palmquist, 2005). Our findings suggest that the deciding factor in increasing green performance value with decreasing institutional and management costs may be the formative trading of cost-effective green technologies (both methods and machine) with small and medium enterprises. This trading is mediated by the international networks and strategically-planned supply-chain transparency initiatives of industrial organizations. It includes positive impact materials (with embodied machine value) traded from emerging market vendors, as well as cost-effective transformation of negative impact products (that previously had to be disposed of in non-tradable dumps at increasing costs) into recyclable products (that the small and medium enterprises in emerging global geographies proficient in green recycling methods are willing to exchange and even compensate).

The third is the research on managing green transformation using the conscious organizational planning perspective. Scholars observe that green transformation entails both capital as well as operating investments (United Nations Environment Program, 2011). Green transformation motivates industrial organizations to increase the value of their machinery power (green capital investment) and method power (green process investment), and reduce the value of their manpower (entropy in negative ecological-impact jobs), material power (entropy in material cost due to conscious efficient use and reuse initiatives), and marketing power (entropy in negative ecological-impact gross value added). Consequently, the entire industrial organization system as a whole experiences increasing capital costs and decreasing operating benefits. As a result, green transformation makes sense only under a conscious organizational planning scenario, where the institutions (formal and informal) and the organizations (small and medium enterprises as well as large firms) work individually towards a common national vision of promoting psychological consciousness among the citizens about the social benefit multiplier of investments by the industrial organization sector. In that scenario, citizens become willing to increase their compensatory consumption of green products, contributing to increasing the value of manpower (growth in green jobs for servicing the entire global universe), material power (freedom from rising material cost constraints, because of efficient use and reuse), and marketing power (value premium for being green), and reducing the cost value of machinery power (lower life cost of machinery due to energy-efficient designs) and method power (savings from positive ecological processes). The dynamic conscious planning cycle of exchanging increasing economic costs of proactive green programing for increasing economic benefits of active green performance may break down if global institutions and/or industrial organizations put disproportionate weight on frontloaded costs, and disproportionately discount exchange costs because of nationalistic concerns that are typical in vibrant democratic conditions. Our findings suggest that global institutions and industrial organizations may potentially be able to free themselves from the upfront cost of increasing green technological investment (comprising of machinery and method powers) and of decreasing non-green technological growth (comprising of man, material, and marketing powers), if they develop strategic awareness about the green technological capability of the small and medium 
enterprises in various local geographies, and develop green technological trading linkages (both for exchanging inputs as well as for servicing outputs). By integrating green local inputs into their present global value chains, and by servicing their non-green outputs for local green processing, industrial organizations can spontaneously become leaders in green consciousness and then focus their entire energy on reducing their technological cost and increasing their technological benefits in the present moment - instead of waiting for that to eventually manifest.

\subsection{Future implications}

Our study also has implications for future work. The survey-based indicators using crosssectional data that we relied on allowed us to apply insights from the dynamic conditionality equations to test Friedman's doctrine using a sample of SMEs from an emerging market. However, we relied on indirect proxies for organization and social culture effect, and for corporate effect and profit maximization motive. Future research should authenticate these findings in alternative samples and contexts, using a more direct measure. Also, the sequential process through which firms achieve green programing should also be empirically verified.

Contingent on the context, the underlying causative factors may vary, and may take a variety of forms. For instance, we assumed the perspective that the formative productmarkets will more likely reflect the green consciousness of contemporary society. However, it is possible that some normative productmarket contexts have evolved stronger green consciousness. For instance, in many traditional societies, environmentally conscious practices are ingrained as part of the work culture; but as these societies adopt international practices, they begin embracing products with harmful chemicals or with a high environmental footprint. In such a scenario, product market context normativity will be positively, not negatively, associated with green programing. Therefore, in future research, it will be important to identify the factors that shape specific empirical contexts.

\section{References}

Angus-Leppan, T., Metcalf, L., \& Benn, S. (2010). Leadership styles and CSR practice: An examination of sensemaking, institutional drivers and CSR leadership. Journal of Business Ethics, 93(2), 189-213.

Anthony, S., \& Schwartz, E. (2017). What the best transformational leaders Do. Harvard Business Review. Retrieved from https://hbr.org/2017/05/ what-the-best-transformational-leaders-do

Craighead, C. W., Ketchen D. J. Dunn, K. S., Hult. G. T. M. (2011). Addressing common method variance: Guidelines for survey research on information technology, operations, and supply chain management. IEEE Transactions on Engineering Management, 58(3), 578-588.

Drnevich, P., \& Kriauciunas, A. (2011). Clarifying the conditions and limits of the contributions of ordinary and dynamic capabilities to relative firm performance. Strategic Management Journal, 32, 254-279.

Duncan, S., \& Barrett, L. F. (2007). Affect is a form of cognition: A neurobiological analysis. Cognition and Emotion, 21(6), 1184-1211.

Eesley, C. E. \& Roberts, E. B. (2010). Cutting your teeth: Learning from entrepreneurial experiences. (Working Paper), Stanford University. Retrieved from. https:/www.researchgate.net/ publication/228367183_Cutting_Your_Teeth_ Learning_from_Rare_Experiences

Ferris, A. E., Garbaccio, R., Marten, A., \& Wolverton, A. (2017). The impacts of environmental regulation on the U.S. economy. Oxford Research Encyclopedia of Environmental Science. doi: 10.1093/ acrefore/9780199389414.013.396 
Friedman, M. (1962). Capitalism and freedom (40th ed.). Chicago, US: University of Chicago Press.

Ghemawat, P. (2007). Redefining global strategy: Crossing borders in a world where differences still matter. Cambridge, MA: Harvard University Press.

Goodstein, E., (2011). Economics and the environment (6th ed.). New York: John Wiley and Sons.

Groner, R., Groner, M., \& Bischof, W. F. (1983). Methods of heuristics. Hillsdale, N. J.: Lawrence Erlbaum.

Grossman, G. M., \& Krueger, A. B. (1991). Environmental impacts of a North American free trade agreement (Working Paper $\mathrm{N}^{\circ}$ 3914). Retrieved from National Bureau of Economic Research. https://www.nber.org/papers/w3914

Gupta, V. (1998). A dynamic model of technological growth: Diffusion of Japanese investment networks overseas (Masters dissertation). The Wharton School of the University of Pennsylvania. Retrieved from https://repository.upenn.edu/dissertations/ AAI9913463/

Gupta, V., \& Zhang, Y. (2019). Strategic fit: Microfoundations of firm's environmental performance. Management Research: Journal of the Iberoamerican Academy of Management, 17(2), 221-246.

Hart, S. L. (1995). A natural-resource-based view of the firm. Academy of Management Review, 20(4), 986-1014.

Hardcopf, R., Shah, R., \& Mukherjee, U. (2017). Explaining heterogeneity in environmental management practice adoption: A multi-level approach (Working Paper). Retrieved from University of Minnesota.
Harman, H. H. (1976). Modern factor analysis (3rd ed.). Chicago: The University of Chicago Press.

Hoffman, J., \& Nembhard, J. (2014). The economics of illusion and environmental justice (Working Paper No 2014-01), John Jay College of Criminal Justice Department of Economics. Retrieved from http://www.johnjay.cuny.edu/ working-paper-series

Hofmann, K. H., Theyel, G., \& Wood, C. H. (2012). Identifying firm capabilities as drivers of environmental management and sustainability practices: Evidence from small and mediumsized manufacturers. Business Strategy and the Environment, 21(8), 530-545.

Jackson, T. (2009). Prosperity without growth. London: Earthscann.

Judge, W. Q., \& Douglas, T. J. (1998). Performance implications of incorporating natural environmental issues into the strategic planning process: An empirical assessment. Journal of Management Studies, 35(2), 241-262.

Kahneman, D. \& Tversky, A. (2000). Choices, values, and frames. Cambridge: Cambridge University Press.

Kim, J., Finkelstein, S., \& Haleblian, J. (2015). All aspirations are not created equal: The differential effects of historical and social aspirations on acquisition behavior. Academy of Management Journal, 58(5), 1361-1388.

Krishnan, R., \& Kozhikode, R. (2015). Status and corporate illegality: Illegal loan recovery practices of commercial banks in India. Academy of Management Journal, 58(5), 1287-3112.

Latouche, M. (2013). Leadershift: Collaboration in the 21st century. USA: Xlibris Corporation.

Lecuona, J. R., \& Reitzig, M. (2014). Knowledge worth having in "excess": The value of tacit and 
firm-specific HR slack. Strategic Management Journal, 35(7), 954-973.

Li, X. C., \& Rowley, C. (2008). The development of Chinese small and medium enterprises and human resource management: A review. Asia Pacific Journal of Human Resources, 46(3), 353379.

Lumpkin, G. T., \& Dess, G. G. (2001). Linking two dimensions of entrepreneurial orientation to firm performance: The moderating role of environment and industry life cycle. Journal of Business Venturing, 16(5), 429-451.

Mabey, C., \& Zhao, S. (2017). Managing five paradoxes of knowledge exchange in networked organizations: New priorities for HRM? Human Resource Management Journal, 27(1), 39-57.

Martínez-Cañas, R., Ruiz-Palomino, P., LinuesaLangreo, J., \& Blázquez-Resino, J. (2016). Consumer participation in co-creation: An enlightening model of causes and effects based on ethical values and transcendent motives. Frontiers in Psychology, 7.

Montoya-Weiss, M., Massey, A. P., \& Song, M. (2001). Getting it together: Temporal coordination and conflict management in global virtual teams. Academy of Management Journal, 44(6), 1251-1262.

Palmquist, R. B. (2005). Property value models. In K. G. Mäler, \& J. R. Vincent (Eds.), Handbook of Environmental Economics (pp. 763-819, v. 2). Elsevier.

Phaneuf, D. J., \& Smith, V. K. (2005). Recreation demand models. In K. G. Mäler, \& J. R. Vincent (Eds.), Handbook of Environmental Economics (pp. 671-761, v. 2). Elsevier.

Porter, M. E., \& van der Linde, C. (1995). Toward a new conception of the environmentcompetitiveness relationship. Journal of Economic Perspectives, 9(4), 97-118
Roper, S., Love, J. H., \& Bonner, K. (2017). Firms' knowledge search and local knowledge externalities in innovation performance. Research Policy, 46(1), 43-56.

Socolow, R., Andrews, C., Berkhout, F., \& Thomas, V. (1994). Industrial ecology and global change. Cambridge, UK: Cambridge University Press.

Suchman, M. C. (1995) Managing legitimacy: Strategic and institutional approaches. Academy of Management Review, 20, 571-610.

Talbot, D. \& Boiral, O. (2017). GHG reporting and impression management: An assessment of sustainability reports from the energy sector. Journal of Business Ethics, 147(2), 367-383.

Teece, D. J., Pisano, G., \& Shuen, A. (1997). Dynamic capabilities and strategic management. Strategic Management Journal, 18(7), 509-533.

Tirole, J, (2008). Some economics of global warming. Rivista di Politica Economica, 98(6), 9-42.

United Nations Environment Program (UNEP). (2011). Decoupling natural resource use and environmental impacts from economic growth. Retrieved from encurtador.com.br/itDSX

United States Census Bureau (2008). Pollution abatement costs and expenditures: 2005. Washington, DC: U.S. Government Printing Office.

Utterback, J. M., \& Abernathy, W. J. (1975). A dynamic model of process and product innovation. Omega, 3(6), 639-656.

Waldman, D. A., Ramirez, G. G., House, R. J., \& Puranam, P. (2001). Does leadership matter? CEO leadership attributes and profitability under conditions of perceived environmental uncertainty. Academy of Management Journal, 44(1), 134-143. 
Waldman, D. et al. (2006). Cultural and leadership predictors of corporate social responsibility values of top management: A globe study of 15 countries. Journal of International Business Studies, 37(6), 823-837.
Zott, C. (2003). Dynamic capabilities and the emergence of intraindustry differential firm performance: insights from a simulation study. Strategic Management Journal, 24(2), 97-125. 


\section{Authors:}

1. Vipin Gupta, Ph.D., California State University, San Bernardino, USA. E-mail: vgupta@csusb.edu ORCID

(iD) 0000-0002-6808-0110

2. Yi Zhang, Ph.D., Zayed University, Abu Dhabi, UAE.

E-mail: zhangyi8773@hotmail.com

ORCID

(iD 0000-0002-0452-7446

\section{Contribution of each author}

\begin{tabular}{lcc}
\hline Contribution & Vipin Gupta & Yi Zhang \\
\hline 1. Definition of research problem & $\sqrt{ }$ & \\
2. Development of hypotheses or research questions (empirical studies) & $\sqrt{ }$ \\
3. Development of theoretical propositions (theoretical Work) & $\sqrt{ }$ \\
4. Theoretical foundation/Literature review & $\sqrt{ }$ \\
5. Definition of methodological procedures & $\sqrt{ }$ \\
6. Data collection & $\sqrt{ }$ \\
7. Statistical analysis & $\sqrt{ }$ \\
8. Analysis and interpretation of data & $\sqrt{ }$ \\
9. Critical revision of the manuscript & $\sqrt{ }$ \\
10. Manuscript Writing & \\
11. Other (please specify which) & \\
\hline
\end{tabular}

